\title{
Fostering a Technologically Innovative Teaching Culture
}

\author{
J. Banks, J. Cheng, S. Payne
}

UTS:Insearch

\begin{abstract}
UTS:Insearch is a pathways provider preparing students from diverse language and learning backgrounds for study in Australia, particularly at UTS. With education increasingly moving towards technology enhanced delivery we identified the need to use these approaches with our students, however as a starting point realised that for this to be successfully embedded into our subjects we would have to create a technologically innovative teaching culture amongst our teaching staff. In fostering this culture the organisation needed to clearly articulate the concept of 'blended learning' to our teaching staff. Following this a suite of strategies to engage teaching staff with diverse understandings of technology enhanced teaching and the opportunities it offers for improving students' learning experiences and understanding were implemented. The strategies that were most successful were those that were 'hands on' and employed blended learning approaches where teaching staff could experience first-hand how students could be engaged with content through the appropriate and meaningful use of technologies. While the project is on-going, the approach has led to $76 \%$ of the learning strategies in our subjects either well progressed or fully compliant with a blended learning approach within a year.
\end{abstract}

Keywords: innovation; teaching culture; blended learning

\section{Introduction}

UTS:Insearch is the premium pathways provider to the University of Technology, Sydney (UTS), one of Australia's leading universities. At UTS:Insearch students are prepared for Undergraduate study at UTS through provision of leading academic English programs, UTS Foundation Studies (on behalf of UTS) and a broad choice of higher education diplomas including Business, Design, Science, Engineering, Information Technology and Communication. Our students are primarily international from a variety of Asian, sub-continent and Middle Eastern learning and language backgrounds. In 2014 in response to the diverse learning and language backgrounds of our students and in recognition that for all students in the 21st century learning is situational, complex, diverse and rapidly changing, and where students need to be able to connect understanding across disciplines, UTS:Insearch began to introduce blended learning approaches into the learning and teaching activities of its academic programs with the intention of having a significant proportion of subjects employing elements of blended learning from Semester 1, 2015. The aim was to create a curriculum that provides students with an environment where learning occurs through seamless integration of technology-enhanced strategies and face-to-face activities, characterised by the best features of interaction within a subject that will promote academic enhancement and innovation in learning and teaching.

Underpinning this, we recognised the need to create a teaching culture in which innovation and embracing of change is the norm, and where the learner and the quality of their learning experience is central to our practice. To foster this culture we introduced initiatives that provided our teaching staff with supportive professional development opportunities that help them feel comfortable and safe in using a range of technologies in relation to their own and students' learning experiences. We contend that by encouraging this technologically innovative teaching culture among our staff blended learning can be embedded in our practice as a 'natural component'. 


\section{Methods}

Our starting point was the development of a clear understanding of what a 'blended learning approach' meant in our context. As outlined in Table 1 below, a wide variety of definitions exist that attempt to delineate what 'blended learning' actually comprises, although some argue "that the phrase 'blended learning' is meaningless, and that it has gained considerable currency in both commercial and educational contexts because of its ambiguity" (Oliver and Trigwell, cited in Chew et al 2010). It was also noted by Partridge et al (2011) that a key challenge in developing a blended learning project is the "lack of a universally accepted definition".

Table 1. Definition of blended learning by various researchers

\begin{tabular}{|c|c|}
\hline Researchers & Definitions of Blended Learning \\
\hline Thorne (2003) & $\begin{array}{l}\text { Represents an opportunity to integrate the innovative and technological advances offered } \\
\text { by online learning with the interaction and participation offered in the best of traditional } \\
\text { learning. }\end{array}$ \\
\hline $\begin{array}{l}\text { Graham, Allen and } \\
\text { Ure (2003); } \\
\text { Graham (2006) }\end{array}$ & $\begin{array}{l}\text { (1) combination of delivery media and tools employed (Singh and Reed, 2001; Orey, } \\
\text { 2002; } \\
\text { (2) combination of a number of pedagogical approaches or instructional methods } \\
\text { (Driscoll, 2002; Rossett, 2002); and } \\
\text { (3) Combination of face-to-face traditional learning with online instruction (Reay, } \\
\text { 2001; Rooney, 2003; Ward and La Branche, 2003). } \\
\text { The first two positions above dilute the definition of blended learning and do not clearly } \\
\text { define what blended learning is. The first two definitions provide an amorphous idea that } \\
\text { almost anything can be defined as blended learning. It would be difficult to find any } \\
\text { learning system that did not involve more than one media and tools; similarly, it would } \\
\text { be difficult to find any teaching and learning scenarios that did not embrace multiple } \\
\text { pedagogies or multiple instructional approaches. Graham (2006) argues that the third } \\
\text { stance specifies more precisely the meaning of blended learning. }\end{array}$ \\
\hline $\begin{array}{l}\text { Vaughan and } \\
\text { Garrison (2005) }\end{array}$ & $\begin{array}{l}\text { The thoughtful integration of face-to-face classrooms (spontaneous verbal discourse) and } \\
\text { Internet based (reflective text-based discourse) learning opportunities is neither an add- } \\
\text { on to a classroom lecture nor an online course. It is the fundamental redesign and an } \\
\text { optimal (re)design approach to enhance and extend learning by rethinking and } \\
\text { restructuring learning and teaching to create blended learning. }\end{array}$ \\
\hline $\begin{array}{l}\text { Littlejohn and } \\
\text { Pegler (2007) }\end{array}$ & $\begin{array}{l}\text { The "blend" which may refer either to the combination of e-learning with other } \\
\text { approaches such as face-to-face instruction, or the mixture within the e-learning mix of } \\
\text { media. }\end{array}$ \\
\hline $\begin{array}{l}\text { Sloan-Consortium } \\
\text { (Vignare, 2007, } \\
\text { pp.38) }\end{array}$ & $\begin{array}{l}\text { (1) the integration of online with face-to-face instruction in a planned, pedagogically } \\
\text { valuable manner and } \\
\text { (2) do not just combine but trade off face-to-face time with online activity (or vice } \\
\text { versa). }\end{array}$ \\
\hline Allan (2007. pp.4) & $\begin{array}{l}\text { (1) The use of different internet-based tools including chat rooms, discussion groups, } \\
\text { Podcasts and self-assessment tools to support a traditional course and } \\
\text { (2) A mixture of face-to-face and e-learning. }\end{array}$ \\
\hline $\begin{array}{l}\text { Garrison and } \\
\text { Vaughan (2008) }\end{array}$ & $\begin{array}{l}\text { No more about reshaping and enhancing the traditional classroom than it is about } \\
\text { making e-learning more acceptable. It necessitates that educators question what is } \\
\text { important and consider how much time should be spent in the classroom. }\end{array}$ \\
\hline
\end{tabular}

Taken from Chew et al 2010, page 3.

To ensure a clearly articulated starting point to our project that could later serve as a reference point for teaching staff, a Blended Learning Working Group was established in August 2013 to research and discuss how this concept was being understood and implemented in other education organisations, and how these experiences might inform our project. Given the plethora of definitions that emerge from technological, instrumental, pedagogic and educational theoretical perspectives we considered the best 'advice' was that our blended learning approach needed to respond to research, the needs of the organisation and our learners (Allan, cited in Chew et al 2010) and keep in 
mind that our 'blend' was one that could be dynamic, transforming over time as research, needs and technologies change. The Working Group ultimately developed a definition of how blended learning sat within an UTS:Insearch context: "A learning environment where students learn through seamless integration of technologyenhanced strategies and face-to-face activities, characterised by the best features of interaction within a subject."

The Blended Learning Working Group also evaluated the level of understanding teaching staff had of blended learning. This qualitative evaluation was conducted by surveying curriculum materials, teacher discussions and classroom observations. We found that the concept of a 'blended learning approach' was new to many of our teaching staff, and was met with a degree of scepticism by some. Certain teachers were of the opinion that the notion was 'just another education fad' and we would be 'back to chalk and talk in five years', while others had concerns about the amount of time it would take to 'blend' their subjects, and some were concerned about having to use technology within their subjects because they were less competent in their use. At the other end of the continuum, we also had a number of early adopters who had already begun using some aspects of blended learning in their classes. These early adopters were an important resource in promoting the use of blended learning approaches in our subjects because, as peers, they were able to demonstrate on a practical level how different technologies could be used to enhance delivery and student experience and achievement. For those teachers who felt less confident in their use of technology and those who had become somewhat ossified in their current practice we also needed to promote a growth mind set (Dwerk 2006) that would encourage teachers to try new approaches and technologies and see themselves as learners who have the capacity to learn and improve their skillset (Gerstein 2014).

To encourage acceptance of the concept, and in addition to encouraging our early adopters to share their experiences, we chose a 'softly, softly' approach to allow sceptical and ambivalent teachers to become accustomed, and less resistant, to the idea and to start exploring ways that would work for them in their classes and with their teaching style and subject matter. Our overriding message to all teaching staff was that blended learning approaches in their subjects must be led by their interpretation of the subject matter to find the best approach to make it accessible to the students (Mishra and Koehler 2006). We stressed that the enhancement of delivery and student experience and achievement was at the core of the approach, not simply the use of one or more technologies, and we actively discouraged the perception that simply 'tacking on' a technology would be acceptable. This multimodal conceptual model seeks to meet the needs of our diverse student population and largely reflects the six basic pedagogical objectives and activities outlined by Picciano (2009). With these considerations as a starting point we undertook a number of initiatives to begin enculturating teaching staff to blended learning that demonstrated our definition of "technology-enhanced strategies and face-to-face activities" both from a theoretical standpoint, by providing scholarly articles that discussed the efficacy, challenges and possibilities of blended learning approaches, and a practical standpoint by modelling practices, applications and software that could be used by teachers in the delivery of their subjects. These initiatives were:

- Establishing various online UTS:Insearch sites, such as:

o 'yammer' to encourage online collaboration and discussion; 
o 'Pinterest', allowing staff to view articles discussing case studies, collaborative technologies, use of social media in education, teaching with technology, and general information on the research underpinning the approach;

o 'symbaloo' with links to various online resources and apps that teaching staff could use as a 'tool box';

- Emailing weekly 'discussion articles' to all teaching staff, giving teaching staff the opportunity to make comments via yammer;

- Providing professional development days to showcase different technologies and give teaching staff opportunities to interact with them and allow early adopters to present on their experiences;

- Providing workshops on the use of blended learning in other areas of the wider UTS institution;

- Appointment of a Learning Technology Coordinator who was also a teacher within one of the UTS:Insearch programs to act as a mentor to assist teachers in incorporating various technologies into the delivery of their classes;

- Establishing a work pod in the teaching staff work area for teachers to investigate and familiarise themselves with appropriate technologies at their own pace.

An action research approach was taken to examine the success of UTS:Insearch's approach. Action research was deemed the best approach because the primary reason for using this research method is to assist the improvement and refining of actions and, in relation to education, gauging the effectiveness of teaching and development of students (Sagor, 2000). An additional consideration was that new programs were being introduced at UTS:Insearch in both Foundation and Diploma areas where blended learning approaches were integral and this method would allow us to both identify successes and areas for improvement, and then refine our approaches, use of technology and content to better meet the needs of our diverse student population.

\section{Results and Discussion}

While the Blended Learning Working Group began working with teaching staff from 2013, the blended learning strategy was not rolled out within subjects until 2014. This lead time allowed the Working Group to consistently articulate its aim of creating enhanced opportunities for teacher-student interaction, increased student engagement, added flexibility to the learning and teaching environment, and to provide opportunities for continuous improvement within subjects through a blended learning approach. We had the opportunity to discuss with teaching staff how blended learning approaches increased interaction between teachers and students, and students and students and have been demonstrated as promoting richer in-class interactions via increased class discussions and higher level exploration of concepts (Association for the Advancement of Computing in Education, 2007). We reiterated that this approach had the potential to not only improve student experience and achievement, but more authentically prepare them for future study and professional lives, and were able to demonstrate to our staff that they were a pivotal and valued component of the success of the project.

UTS:Insearch's academic teaching staff is comprised of around 130 teaching staff, all employed on a sessional basis, working across Foundation and Diploma levels. They 
teach International students with a minimum of IELTS 5.5 for Foundation and IELTS 6 for Diploma, and Domestic students. The Foundation program is a generalist pathways program, while the Diplomas teach first year Undergraduate programs in the areas of Business, Engineering, Science, Communication, Information Technology and Design. Teaching staff have various combinations of a degree in their subject area and/or a teaching degree and/or professional experience. The average age of teaching staff is 47 years, and the average length of time teachers have worked at UTS:Insearch is eight years. This particular teacher demographic in itself presented the Blended Learning Working Group with some challenges:

- The teachers were not 'digital natives' and had widely varying experience and/or confidence in the use of technologies;

- There was varying acceptance/interest in the idea of changing teaching practices which they felt were 'tried and true' - an 'if it ain't broke don't fix it' attitude;

- Due to the unpredictable nature of sessional employment there can be a tendency for some teachers to feel there is little personal gain in modifying habitual practices resulting in less acceptance of change.

UTS:Insearch values its teaching staff and their contribution to the organisation and student achievement, so a conscious decision was made to try to bring existing staff, who have a very comprehensive knowledge of content, on a learning journey rather than recruit new teaching staff. As the organisation is a small one, support for the teachers and the process was drawn from the active leadership of the Blended Learning Working Group and early adopters within the current staff. As previously discussed, our approach to blended learning is understood as the use of technology to support and enhance students' interaction with teachers, each other and content. It also recognises the centrality of the role of the teacher in creating more interactive approaches which potentially create classroom cultures that are co-constructed, redefined and modified as the students move through online and face-to-face activities and teaches students to mediate their own, and other students', learning (Takahashi, Austin \& Morimoto, 2000). Additionally, this conceptualisation which asks teachers to draw upon their "pedagogical content knowledge" to best select the technologies and approaches “...most germane to its teachability” (Shulman, 1986) invites them to examine their subject content to identify how to enhance their teaching practice and their students' learning and understanding.

By having over a year's 'lead in' time before the strategy was rolled out the Working Group was able to incrementally break down many of the barriers teachers initially had about the concept of blended learning, of the difficulties they may have with the technology, and create an acceptance that this approach was to be 'standard practice' within UTS:Insearch. In addition to being supportive of the teachers' central role in moving to blended learning approaches and practices, initiatives were undertaken to enculturate the teaching staff to the concepts. These initiatives, outlined previously, met with various levels of success:

- The take-up of online resources was, and continues to be, low with teachers feeling that having to log on to another site to comment or read articles was an impost on their time. While some teachers continue to use yammer, Pinterest 
and Symbaloo have had little patronage and their impact on enculturating staff has been minimal.

- Directly emailing staff with discussion articles initially appeared to have little impact as teaching staff were not commenting on the articles nor did they appear to be involved in any easily discernible discussion about them. However as professional development days progressed there appeared to be more interest, with teaching staff replying to the emails with their opinions and observations, rather than using yammer, and teachers commenting in person that the emails gave them new ideas and more information about the concept, how they might approach it, and how this would benefit their students.

- Initial professional development days were cautiously greeted by teachers both in terms of content and format. We departed from the 'usual chalk and talk' format to a more interactive workshop style demonstrating the principles on which our approach was based. This proved popular with teachers and attendance at professional development days has increased from an average of $10 \%$ of staff to an average of $40 \%$. Teachers also report a preference for this format, finding professional development days more enjoyable and relevant to their practice, allowing them to directly experience how a blended learning approach can improve learning experiences.

- The appointment of a Learning Technology Coordinator (LTC) was an important step forward in the enculturation process. As a peer, the LTC was able to demonstrate within our context how the principles and practices could be implemented and provide support and suggestions to fellow teachers in a very accessible way. The LTC also identified a number of key applications for teachers to be able to use easily, and which students enthusiastically engaged with in class. In this on-going role, the LTC works individually with teachers assisting them with support and selecting applications that best enhance the content and meet the teachers' needs.

- The provision of iPads and various Android devices has been moderately successful, with time constraints on teaching staff being the largest issue affecting their use.

The varying success of the approaches served as an important learning exercise for both the Blended Learning Working Group and for teaching staff. The differing levels of uptake demonstrated what types of technologies and applications people are willing to engage with, allowing individual teachers to reflect on what they might choose to implement as part of blended learning in their subjects.

While the introduction of blended learning approaches as part of the teaching culture at UTS:Insearch is still in its infancy, we feel the approach the Blended Learning Working Group took in slowly enculturating teaching staff to the concept while clearly valuing their roles has been successful. At the conclusion of Semester 3 2014, Subject Coordinators completed a survey to indicate the level at which blended learning was embedded in their subjects. The survey indicated that in regards to embedding blended learning approaches to learning strategies, on average, $38.39 \%$ of subjects were fully compliant; $37.5 \%$ well in progress; $17.86 \%$ in progress; $1.78 \%$ unclear on how to go about this; and $4.46 \%$ not commenced. 


\section{Conclusions}

Our project identified that the successful implementation of a blended learning approach to learning and teaching required UTS:Insearch to develop a technologically innovative teaching culture that was based on a very clear understanding of what this was in our context. To foster this culture we slowly introduced the concept to teaching staff, while encouraging them adopt a growth mind set by learning more about the approach and clearly articulating their importance in the project. We also adopted a number of initiatives, but found those that were more 'hands on' were more successful in communicating the approach to teaching staff. Having the teaching staff engaged and supportive of a blended learning approach allows us to better and more 'naturally' embed learning strategies that engage students, and teachers, enhance our students' learning experience and more authentically prepare them for future study and work. By approaching the introduction of the concept in a gradual, supportive manner where we continuously stressed that pedagogy leads technology we were able to encourage our teaching staff to adopt a non-traditional approach to their practice and to begin building a dynamic and innovative teaching culture within our organisation.

\section{References}

Association for the Advancement of Computing in Education (2007), Perspectives on blended learning in higher education. http://ablendedmaricopa.pbworks.com, accessed 30/12/2014.

Chew, E., Turner, D. A., \& Jones, N. (2010). In Love and War: Blended Learning Theories for Computer Scientists and Educationists. In F. L. Wang, J. Fong,

\& R. C. Kwan (Eds.), Handbook of Research on Hybrid Learning Models: Advanced Tools, Technologies, and Applications (pp. 1-23). Hershey, PA:

Information Science Reference. Retrieved from http://www.igiglobal.com.ezproxy.lib.uts.edu.au/gateway/chapter/full-text-pdf/40366

Dweck, Carol S. (2006) Mindset: The New Psychology of Success. New York: Random House.

Gerstein, Jackie. "The Educator with a Growth Mindset: A Staff Workshop." User Generated Education. August 28, 2014.

https://usergeneratededucation.wordpress.com/2014/08/29/the-educator-with-agrowth-mindset-a-staff-workshop/ accessed 26/11/2014.

Mishra, P., \& Koehler, M.J. (2006) Technological Pedagogical Content Knowledge: A framework for teacher knowledge. Teachers College Record, 108 (6), 1017-1054.

Partridge, H., Ponting, D., \& McCay, M. (2011) Good Practice Report: Blended Learning. Australian Learning and Teaching Council Ltd, an initiative of the Australian Government Department of Education, Employment and Workplace Relations.

Picciano, A.G. (2009). Blending with a Purpose: The Multimodal Model. Journal of Asynchronous Learning Networks, 13(1), pp. 7-18.

Sagor, R. (2000). Guiding School Improvement with Action Research. Alexandria: Association for Supervision \& Curriculum Development (ASCD). 
Shulman, L.S. (1986). Those who understand: Knowledge growth in teaching. Educational Researcher, 15(2), pp. 4-14.

Takahashi, E., Austin, T. and Morimoto, Y. (2000). 'Social Interaction and Language Development in a FLES Classroom'. Second and foreign language learning through classroom interaction. Hall, J. C. and Verplaetse, L. S. (eds), New Jersey: Lawrence Erlbaum Associates, pp.139- 157. 